\title{
A epêntese consonantal em português e sua interpretação na Teoria da Otimalidade*
}

\author{
Luiz Carlos Cagliari \\ Universidade Estadual de Campinas - UNICAMP \\ Gladis Massini-Cagliari \\ Universidade Estadual Paulista - UNESP/Araraquara
}

\section{Abstract}

A study of the consonantal epenthesis in Portuguese, interpreted according to the Theory of Optimality framework, is presented in this article. The featural nature of the epenthetic consonants is defined, as well as the context of their occurrence. The implication to the word derivational process is commented on. Consonantal epenthesis in Portuguese is in close relationship with sandhi and liaison processes. 


\section{INSERÇÃO DE SEGMENTOS}

$\mathrm{N}$

a fonologia, há vários processos que dizem respeito à inserção de um segmento dentro de palavras. ${ }^{1}$ Além do termo inserção, o termo epêntese refere-se, de um modo geral, ao acréscimo de um segmento a uma palavra (CONTRERAS, 1977; FOURAKIS \& PORT, 1986; HARRIS, 1987). Quando a adição de um segmento acontece no início de uma palavra, o termo mais específico para esse processo é prótese (1a). Se ocorrer o acréscimo de um segmento no final de uma palavra, o processo de inserção tem o nome específico de paragoge (1b). ${ }^{2}$ Esses processos receberam uma atenção especial nos estudos de Lingüística Histórica (ANDERSON, 1991:188) e, antes, dos estudos filológicos (HUBER, 1986:155-160; ALI, 1971: 229-247).

$\begin{array}{llll}\text { (1) a. } & \text { lembrar } & \text { [alẽmbrar] } \\ & \text { b. } & \text { UNESP } & \text { [unespi] }\end{array}$

A epêntese pode ser vocálica ou consonantal. Neste trabalho, somente a epêntese consonantal será estudada.

Um tipo especial de epêntese ou inserção tem recebido o nome de consoante ou vogal intrusiva (ALI et alii, 1979). Os elementos intrusivos caracterizam-se por adicionar um segmento a uma palavra sem justificação etimológica. Em outros termos, isto significa que ocorre apenas um ajustamento fonético e, em geral, determina uma pronúncia estigmatizada ou não-padrão. Os segmentos intrusivos têm, em geral, o efeito de facilitar uma pronúncia ou a percepção de seqüências de segmentos sonoros, adequando-se foneticamente ao contexto em que ocorrem, por exemplo, revelando um fenômeno de assimilação, como a presença de consoantes homorgânicas. ${ }^{3}$ 
WETZELS (1985) e CLEMENTS (1988:16) analisam os casos de consoantes oclusivas intrusivas em inglês, mostrando que, embora se possa definir contextos e processo, e até uma divisão em dois tipos de processos, não existe uma razão maior ${ }^{4}$ para que as palavras acrescentem esses elementos. Alguns exemplos do inglês são apresentados em (2). ${ }^{5}$

$\begin{array}{ll}\text { (2) dense } & \text { den }(\mathrm{t}) \text { se } \\ \text { false } & \text { fal(t)se } \\ \text { hamster } & \text { ham }(\mathrm{p}) \text { ster } \\ \text { wealthy } & \text { weal(t)thy }\end{array}$

Para interpretar corretamente as consoantes intrusivas dentro do modelo de Geometria de Traços, CLEMENTS (1987) propôs a criação de um nó chamado Cavidade Oral, CO (Oral Cavity), ao qual se liga o traço [contínuo]. Por um processo de espraiamento, o nó CO liga-se ao nó Supralaríngeo, ao qual estão ligados os traços [sonorante] e [nasal]. Com essa "assimilação", cria-se um segmento intercalado com os traços do nó CO do elemento anterior e com os traços do nó Supralaríngeo do elemento posterior. Esse modo de interpretar a inserção como uma assimilação veio reforçar a idéia de um segmento de contorno na Fonologia de Geometria de Traços.

A Língua Portuguesa não apresenta exemplos de ocorrência de consoantes intrusivas, a não ser em uma perspectiva diacrônica (HUBER, 1986: 155-160). Uma pesquisa cuidadosa talvez encontre, na fala popular, exemplos atuais de consoantes intrusivas.

De acordo com a Teoria da Otimalidade (de agora em diante TO), proposta inicialmente por PRINCE \& SMOLENSKY (1993), ${ }^{6}$ todo segmento que for acrescentado ao output representa uma violação de uma restrição chamada DEP-IO, definida em (3). Essa restrição faz parte de uma teoria geral da gramática relativa à dependência ou correspondência do output com relação ao input (CASALI, 1996: 16-17; SHERRARD, 1997: 68).

(3) Dep-IO: todo elemento de $S_{2}$ tem um correspondente em $S_{1}{ }^{7}$ 
Como observam McCARTHY \& PRINCE (1997: 60), a restrição DEP-IO deverá ser especificada com relação aos elementos envolvidos, se vogal ou consoante. De acordo com a TO, portanto, todo segmento que aparecer no output sem ter um correspondente no input estará violando a restrição DEP-IO. Como a língua portuguesa tem palavras nas quais aparecem consoantes epentéticas, a violação a essa restrição será suportável. A não-violação dessa restrição acarretará uma violação fatal de uma outra restrição que obriga a inserção da consoante. A obrigatoriedade da epêntese pode ser estabelecida através de uma restrição geral do tipo EPEN-C, como se define em (4).

(4) Epen-C: o output deverá conter uma consoante epentética na juntura de morfemas, dentro de palavras.

Neste trabalho, serão consideradas apenas as inserções consonantais que ocorrem no processo de derivação das palavras, quando se acrescenta um ou mais sufixos a um radical.

\section{O contexto da epêntese em português}

A epêntese consonantal em português ocorre apenas na juntura morfemática interna de palavras derivadas. O objetivo da epêntese é evitar o hiato na juntura dos morfemas. Não aparece consoante epentética entre um prefixo e um radical. Os encontros vocálicos, que podem acontecer nesse caso, formam hiatos (5). ${ }^{8}$

$$
\text { extra-ordinário }
$$

so-erguer

re-organizar ${ }^{9}$

A forma típica de uma palavra derivada em Português é constituída por um radical e por um ou mais afixos, os quais podem ser prefixos ou sufixos (6a). O processo de flexão se distingue da derivação (LYONS, 1979:188-195), porque acrescenta morfemas especiais de flexão, como os de gênero e de número (6b) ou os morfemas verbais (6c). 
(6) a. in-felic-idade sub-mar-ino

$\begin{array}{lll}\text { b. livr-o } & \text { livr-o-s } \\ & \text { lat-a } & \text { lat-a-s } \\ \text { c. cant-á-va-mos } & \text { part-i- } \varnothing \text {-mos }\end{array}$

A regra de epêntese aplica-se somente em juntura sufixal interna de palavras derivadas. Como se mostra em (7), os tipos de segmento que ocorrem nesse contexto de juntura morfemática podem variar; no entanto, como se pode observar, nem sempre a sua ocorrência condiciona o aparecimento ou não da epêntese.

(7) a

\begin{tabular}{|c|c|c|c|c|}
\hline \multirow[t]{5}{*}{ a. } & $\mathrm{C}+\mathrm{vt}^{10}$ & alegr + ia & alegr-ia & \\
\hline & & colher + inha & colher-z-inha & \\
\hline & $\mathrm{C}+\mathrm{va}$ & pirat + aria & pirat-aria & \\
\hline & & flúor + ico & fluorí-t-ico & \\
\hline & & metr + ico & métr-ico & \\
\hline \multirow[t]{2}{*}{ b. } & $\mathrm{C}+\mathrm{C}$ & veloz + mente & veloz-mente & \\
\hline & & cruel + dade & cruel-d-ade & cruel-dade \\
\hline \multirow[t]{3}{*}{ c. } & $\mathrm{vt}+\mathrm{C}$ & pagá + vel & pagá-vel & \\
\hline & $\mathrm{va}+\mathrm{C}$ & casa + mento & casa-mento & \\
\hline & & $\operatorname{grat}(i)+$ dão & grati-d-ão & grat(i)-dão \\
\hline \multirow[t]{2}{*}{ d. } & $\mathrm{vt}+\mathrm{vt}$ & chá + eira & cha-1-eira & \\
\hline & & caju + ina & ca.ju.í.na ${ }^{11}$ & \\
\hline e. & $\mathrm{vt}+\mathrm{va}$ & café + ico & ca.féi.co & \\
\hline f. & $\mathrm{va}+\mathrm{va}$ & tema + ico & temá-t-ico & \\
\hline & $\mathrm{va}+\mathrm{vt}$ & casa $+\tilde{a} o$ & casa-r-ão & \\
\hline
\end{tabular}

Um dos contextos mais comuns de derivação ocorre quando o radical termina por consoante e o sufixo começa por vogal tônica ou átona. Neste caso, não costuma ocorrer consoante epentética (7a). A ocorrência do -z-no sufixo -zinha é um caso especial, como se verá mais adiante. O sufixo - ic- (átono) também representa um caso especial, uma vez que costuma vir acompanhado de uma consoante epentética. $^{12}$ 
No contexto em que há duas consoantes ( $7 \mathrm{~b})$, a primeira é um arquifonema /S, R, L, N/ na posição de coda. A consoante inicial do sufixo apresenta alguns problemas de interpretação. O mais comum é admitir que alguns sufixos começam por consoante, quando essas consoantes não são coronais. Se forem coronais, podem ser interpretadas como epentéticas. Alguns autores (entre eles os gramáticos tradicionais), entretanto, atribuem também essas consoantes coronais ao início dos sufixos.

Em alguns casos (7c), a presença da consoante atribuída ao início do sufixo exige a presença de uma vogal no final do radical, a qual pode ter origem diversa (vogal temática verbal, flexão, vogal epentética). Uma análise que considere essas consoantes como epentéticas é possível, sobretudo quando a consoante é coronal, mas não é a maneira tradicional de interpretá-las. Um problema que surge, então, é admitir que haja dois elementos epentéticos: um vocálico e outro consonantal.

Se ocorrer o encontro de duas vogais tônicas, a regra mais comum é a inserção da consoante epentética. No entanto, a língua também admite a formação de hiatos (7d). Se a primeira vogal for tônica e a segunda for átona, pode ocorrer a formação de um ditongo (7e). Quando as duas vogais forem átonas, ocorre a epêntese consonantal (7f). Se a vogal que inicia o sufixo for tônica, a adjunção da consoante epentética pode também ocorrer (7f). Um exemplo como casarão poderia ser interpretado como tendo, na verdade, um sufixo -arão ajuntado ao radical cas-.

Em alguns casos, a inserção ou não da consoante epentética irá denotar uma forma mais ou menos marcada. Por exemplo, se o radical terminar por vogal átona, a epêntese produzirá uma forma mais marcada. Se o radical terminar por consoante, formas sem a epêntese são também marcadas (8).
(8) casa
não-marcada
marcada
mulher
casinha
casazinha
mulherzinha
mulherinha 
Existe uma relação estreita entre a regra de epêntese e as regras de sândi e de liaison. A epêntese aplica-se quando não se aplica a regra de sândi. A regra de sândi ${ }^{13}$ manda eliminar a primeira vogal em juntura de morfemas ou a transformá-la em parte de um ditongo com a vogal seguinte. Na derivação, a regra de sândi não costuma ter contexto de aplicação, sendo seu ambiente típico a juntura intervocabular (9) - (VOGEL, 1986).

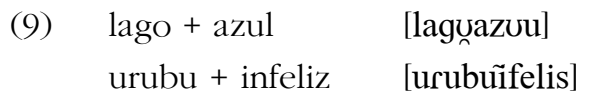

As regras de epêntese e de sândi exigem a aplicação da regra de liaison, que consiste em ressilabificar a consoante da esquerda (do radical ou epentética), fazendo-a ocupar a posição de onset da primeira sílaba do sufixo.
(10)
ca.sa i.nha
ca.si.nha
mu.lher. o.na
mu.lhe.ro.na

Além das restrições colocadas anteriormente (3) e (4), para dar contas dos fatos acima na TO, serão necessárias algumas restrições, apresentadas adiante, que funcionam, em geral, de modo independente. $\mathrm{Na}$ TO, o fenômeno de queda de segmento é tratado como uma violação da restrição MAX-IO, que diz que não se pode perder elemento do imput no output. As restrições SAndhi e NoSAndhi pertencem ao grupo de restrições do tipo MAx. A ressilabificação faz parte da teoria de alinhamento, sendo uma violação de uma restrição do tipo Align (McCARTHY \& PRINCE, 1993). A restrição NoHiatus diz que não se admitem duas vogais contíguas. Esta restrição pertence à teoria do alinhamento e, mais especificamente, ao grupo de restrições do tipo Contig, que rege a contigüidade dos segmentos (fonotática). No caso específico do presente trabalho, a restrição que proíbe o hiato aplica-se apenas na juntura morfológica sufixal interna de palavras. 
(11) MaX-IO: todo elemento de $S_{1}$ tem um correspondente em $S_{2}$.

OnSET: toda sílaba começa por consoante.

NoCoda: as sílabas acabam em vogal.

Align[F]: deve-se manter os segmentos de $\mathrm{S}_{2}$ nas mesmas sílabas de $\mathrm{S}_{1}$.

SANDHI: se houver contexto para a aplicação de sândi em $\mathrm{S}_{1}$, o resultado deverá estar presente em $\mathrm{S}_{2}$.

NoSANDHI: é proibido eliminar vogal em fronteira de juntura.

LiAison: a consoante da Coda de uma sílaba torna-se Onset da sílaba seguinte.

NoHiatus: é proibido ter duas vogais contíguas em $\mathrm{S}_{2}$.

Um exemplo de avaliação da epêntese em português pode ser visto no tableau (13), em que aparece um padrão de input: V(C) + $\mathrm{V}$, que representa o contexto geral de juntura morfemática interna de palavras derivadas com sufixo.

O ranking considera necessária uma violação suportável de DEP-IO para que possa haver a epêntese; por isso, essa restrição ocupa um lugar baixo no escalão. Por outro lado, se a epêntese não ocorrer, acontecerá um hiato ou a aplicação indevida de uma regra de sândi.

(12) Ranking: NoHiatus $>>$ Align $[\mathrm{F}]>>$ NoSAndhi $>>$ DeP-IO ; Onset.

\begin{tabular}{|c|c|c|c|c|c|}
\hline (13) $V(C)+V$ & NoHiatus & AliGN[F] & NoSANDHI & DeP-IO & ONSET \\
\hline a. $\oplus$ nu.dez & & & & $*$ & \\
\hline b. nu.ez & $* !$ & & & & $*$ \\
\hline c. $\sigma^{\circ}$ mar.zi.to & & & & $*$ & \\
\hline d. ma.ri.to & & $* !$ & & & \\
\hline e. ca.fé.zi.nho & & & & $*$ & \\
\hline f. ca.fé.i.nho & $* !$ & & & & $*$ \\
\hline g. ca.féi.nho & & $* !$ & $* !$ & & \\
\hline
\end{tabular}

Para evitar um hiato em *nuez, aplica-se a regra de epêntese, cuja única violação acontece com a restrição DEP-IO. A não-violação de DEP-IO acarreta uma violação fatal da restrição NoHiatus, colocada 
mais alto no ranking. A violação de onseté irrelevante nos candidatos avaliados. Em (13d), houve uma aplicação indevida da regra de liaison, porque não houve a inserção de uma consoante epentética, esperada para aquele contexto. Uma aplicação incorreta da regra de sândi ocorre em (13g), gerando uma violação fatal.

\section{AS CONSOANTES EPENTÉTICAS}

Em Português, as consoantes epentéticas têm o lugar de articulação coronal, como se pode ver nos exemplos abaixo (14).

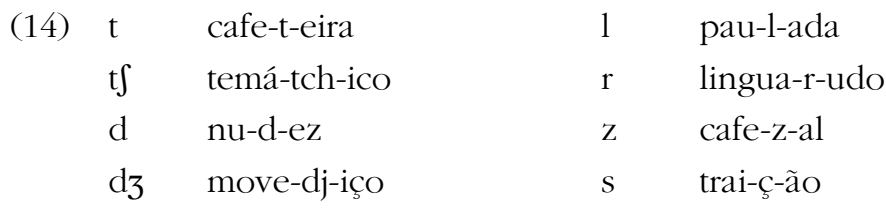

Sem um estudo muito detalhado e profundo sobre o fenômeno, pode não parecer claro por que algumas palavras apresentam uma consoante epentética e outras não. Assim, uma palavra como traição pode ter uma consoante epentética, ou ter um sufixo -ção, começado por [s]. Os exemplos de (15) têm sido interpretados como tendo um sufixo que começa por consoante não-epentética. Um outro modo de ver a questão poderia interpretar essas consoantes como epentéticas.

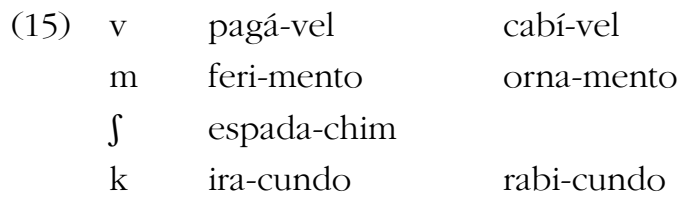

No caso da fricativa [v], embora haja uma distribuição contextual muito favorável a considerar tal consoante como epentética, o fato de não ser coronal destoa da regra geral. O mesmo comentário pode ser feito para os casos apresentados acima, em que ocorre a consoante [m]. Um argumento a favor da consoante epentética [m] surge quando se compararam palavras apresentadas em (15) com palavras como barulb-ento, poeir-ento, derivadas de barulh-e poeir- 
A palavra espadachim veio do Italiano spadaccino, alinhandose com sufixos do tipo -im de flautim. Porém, a interpretação do [f] como consoante epentética destoa das demais que, como vimos acima, caracterizam-se por ser coronais.

Palavras como iracundo e rabicundo poderiam ter sufixos começados por $[\mathrm{k}]$ ou essa consoante poderia ser epentética (cf. palavras como rabicho e irascível).

A epêntese consonantal pode ocorrer também na derivação verbal, embora seja rara. Uma palavra como salforma o verbo salgar com uma consoante epentética [g]. Do verbo vem o adjetivo salgado. Uma interpretação diferente poderia considerar que salgado tem um radical salg-com uma consoante extrassilábica que cai na palavra sal.

No caso de narigudo, pode-se admitir como radical narig-. Assim, a forma nariz seria o resultado da aplicação da regra que transforma oclusivas em fricativas (cf. elétrico - eletricidade). $\mathrm{Na}$ língua, existem também formas como narizudo, narizinbo, (cf. *nariguinbo), narigão, narizão. Interpretar narize narigudo tendo dois alomorfes nariz e narig- não parece ser uma boa análise, porque tal separação é desnecessária.

Para mostrar o fato de as consoantes epentéticas do Português serem coronais e não de outro tipo, pode-se estabelecer uma restrição do tipo FAITH[COR.$^{14}$

(16) Farth[Cor]: as consoantes epentéticas devem ser [coronais].

O ranking da restrição FAITH[COR] exige que ela ocupe uma posição alta, controlando a violação suportável da epêntese na restrição DEP-IO.

(17) Ranking: FaIth[CoR] >> Dep-IO.

\begin{tabular}{|l|c|c|}
\hline (18) ca.fé + ei.r + a & FAITH[COR] & DEP-IO \\
\hline a. ca.fe.tei.ra & $* !$ & $*$ \\
\hline b. ca.fe.kei.ra & $* !$ & $*$ \\
\hline c. ca.fe.mei.ra & $* !$ & $*$ \\
\hline
\end{tabular}


O tableau (21) mostra a avaliação da palavra espadachim. Como se trata de um caso muito particular, a restrição que permite que tal forma seja aceita na língua, concorrendo com outros candidatos possíveis, também deverá ter um caráter muito particular. Como costuma acontecer nesses casos, a restrição tomará a forma negativa de uma restrição geral. Na hipótese de a palavra espadachim ter uma consoante epentética não coronal, a restrição que dará conta desse fato será *FAITH[COR]. ${ }^{15}$

(19) *FAith[CoR]: a consoante epentética não pode ser [coronal]. ${ }^{16}$

(20) Ranking: *Faith[Cor] >> DeP-IO.

\begin{tabular}{|c|c|c|}
\hline (21) es.pa.da $+\mathrm{im}$ & ${ }^{*}$ FAITH $[\mathrm{COR}]$ & DeP-IO \\
\hline a. es.pa.da.chim & & $*$ \\
\hline b. es.pa.da.ssim & $* !$ & $*$ \\
\hline c. es.pa.da.tim & $* !$ & $*$ \\
\hline
\end{tabular}

\section{ALGUMAS QUESTÕES DE DERIVAÇÃO}

Um problema que a morfologia apresenta, e que não tem sido debatido suficientemente, é como as palavras se derivam. Normalmente, uma palavra derivada é formada de um radical mais afixos, categoria em que se inserem os sufixos (ALI, 1971: 229-247; CÂMARA JR., 1985: 216-227; CUNHA, 1978: 62-84). No entanto, como vimos anteriormente, uma palavra como casarão é diferente de casão (inclusive no significado), e apresenta uma vogal - $a$ - na juntura que pode ser interpretada como parte de um sufixo -arão ou como resquício da desinência de gênero da palavra casa que permaneceu na forma derivada. Por outro lado, não é uma interpretação correta considerar que a desinência de gênero de palavras simples esteja sempre presente nas palavras derivadas, como no caso acima. Assim, uma palavra como joelheira é formada de joelh + eira e não de joelho + eira. No entanto, há morfólogos, como MONTEIRO (1991), que 
consideram que, na derivação, ocorre uma elisão da vogal temática nominal diante de sufixo iniciado por vogal. A TO tem uma razão própria para interpretar as palavras derivadas como sendo constituídas de radical mais sufixo, porque, neste caso, não haveria a queda da vogal de flexão, com uma violação do tipo MAx-ıo, o que aconteceria se a derivação fosse do tipo joelho + eira.

O tableau (23) mostra a avaliação de uma derivação do tipo joelh + eira. Nesta derivação, aplica-se a regra de liaison e a restrição MAX-IO não sofre nenhuma restrição. A introdução da desinência de gênero (23b) provoca uma violação fatal de Dep-Io e de SANDHI. O candidato (23c) também cometeu uma violação fatal de DEP-IO, ao introduzir no output uma consoante epentética não-autorizada.

(22) Ranking: DeP-IO > SANDHI $>$ LIAISON $>$ ALIGN[F].

\begin{tabular}{|c|c|c|c|c|c|}
\hline (23) jo.e.lh + ei.r $+\mathrm{a}$ & DEP-IO & SANDHI & LIAISON & MAX-IO & ALIGN[F] \\
\hline a. jo.e.lhei.ra & & & & & $* *$ \\
\hline b. jo.e.lho.ei.ra & $* !$ & $* !$ & & & $*$ \\
\hline c. jo.e.lho.tei.ra & $* !$ & & & & $*$ \\
\hline d. jo.e.lh.ei.r.a & & & $* * * !$ & & \\
\hline
\end{tabular}

Embora o português não goste de ter hiatos, sobretudo em juntura interna de palavras, na língua, há alguns casos em que isso acontece. Com certas palavras, como em (24), a língua admite a presença de hiato e, por esta razão, o léxico acaba ficando com duas palavras, cuja marca diferencial é a presença ou não de uma consoante epentética. Uma vez que há duas palavras, a tendência é encontrar significados diferentes para elas, como aconteceu com as palavras cafeteira e cafeeira - mas, não aconteceu com cajuzeiro e cajueiro.
(24) café
cafe-eira
cafe-t-eira cafe-ina
caju
caju-eiro
caju-z-eiro
caju-ina 
A ocorrência de uma palavra como cafeeira não incorre em um problema de OCP (Princípio de Contorno Obrigatório), ${ }^{17}$ porque existe uma fronteira silábica entre as duas ocorrências de [e], e porque a primeira refere-se a uma vogal monotongo e a segunda à primeira parte de um ditongo. É preciso notar que não se aplica a regra de sândi, quando a primeira vogal da juntura é tônica.

(25) Ranking: MaX-IO $>\operatorname{Epen}(\mathrm{C})>>$ NoHiatus $>$ NoSAndhi $>$ DeP-IO.

\begin{tabular}{|c|c|c|c|c|c|}
\hline (26) ca.fé + ei.r $+\mathrm{a}$ & Max-IO & Epen(C) & NoHiatus & NoS Andhi & Dep-IO \\
\hline a. ca.fe.ei.ra & & $*$ & $*$ & & \\
\hline b. ca.fe.tei.ra & & & & & $*$ \\
\hline c. ca.fe.zei.ra & & & & & $*$ \\
\hline
\end{tabular}

O candidato cafeeira não aplica a regra de $\operatorname{Epen}(C)$ e, como não pode aplicar a regra de sândi, viola também a restrição NoHiATus. Em (26d), uma vogal tônica não pode sofrer queda, porque isso causa uma violação fatal com relação à restrição MAX-IO. Além do mais, viola fatalmente a restrição NoSANDHI.

Um problema que aparece no caso da derivação de palavras como cafezinho e cafeeira refere-se à presença de uma vogal média baixa na primeira palavra e de uma vogal média alta na segunda. Esse fato ocorre com as palavras derivadas, em geral. Quando se acrescenta um sufixo a um radical cuja vogal tônica é média baixa, esta se torna vogal média alta, transformando a sílaba portadora de acento primário em sílaba portadora de acento secundário (27). Entretanto, com os sufixos $-z i n h o^{18}$ e -mente a vogal média baixa do radical se mantém. ${ }^{19}$

\begin{tabular}{|c|c|c|}
\hline só & sózinho & sómente \\
\hline cérto & cértinho & cértamente \\
\hline & certêza & certêiro \\
\hline fé & cafézinho & cafézito \\
\hline & cafêteira & cafêeira \\
\hline
\end{tabular}

cafézão 
Para dar conta de tal fato na TO, será preciso estabelecer uma restrição específica da Língua Portuguesa, que permita a mudança de qualidade da vogal média baixa em média alta. ${ }^{20}$ Tal restrição irá dizer que é proibida a ocorrência de vogal média baixa em sílaba átona - (28). Nas palavras derivadas, a sílaba do radical que tinha o acento primário nem sempre fica com o acento secundário. Por exemplo, em uma palavra como cafezinho é comum um deslocamento do acento secundário à esquerda, passando para a primeira sílaba da palavra. Um exemplo de avaliação é apresentado em (29).

(28) $\operatorname{No}[\varepsilon, o](\breve{\sigma})$ : as vogais [ع,o] são proibidas em sílabas átonas.

IDENT-IO[F]: os segmentos de $S_{1}$ e de $S_{2}$ precisam ter os mesmos traços.

\begin{tabular}{|c|c|c|c|c|}
\hline (29) $/ \mathrm{ka} . \mathrm{f} \varepsilon+$ sufixo & $\operatorname{No}[\varepsilon, \supset](\breve{\sigma})$ & IDENT-IO[F] & NoHiatus & DEP-IO \\
\hline a. ka.fe.zi.nho & $*$ & & & * \\
\hline b. ka.fe.zi.nho & & $* !$ & & $*$ \\
\hline$\leftrightarrow$ c. ka.fe.tei.ra & & $*$ & & $*$ \\
\hline d. ka.fe.tei.ra & $* !$ & & & $*$ \\
\hline e. ka.fe.ei.ra & & $*$ & $*$ & \\
\hline f. ka.fe.ei.ra & $* !$ & & $*$ & \\
\hline
\end{tabular}

Nota-se no tableau acima que as formas admitidas pela língua

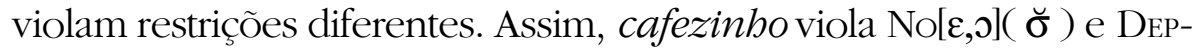
IO; cafeteira viola IDENT-IO[F] e DeP-IO e cafeeira viola IDENT-IO[F] e NoHiatus.

Uma questão não muito clara no processo de derivação acontece com palavras que apresentam uma vogal no fim do radical e uma consoante na juntura, sendo que esses dois elementos poderiam ser tratados como epentéticos. O problema reside justamente no fato de se ter dois elementos epentéticos, quando, em princípio, deveria bastar apenas um. Para evitar esse tipo de dificuldade de interpretação, é mais comum propor apenas a consoante como epentética. Com alguns sufixos, é possível até incorporar a vogal como elemento inicial do sufixo e, dessa forma, não haveria nenhuma consoante epentética. 
(30) prato prat-e-l-eira prate-1-eira

digno dign-i-d-ade digni-d-ade dign-idade

Palavras derivadas de verbos trazem consigo elementos verbais, como a vogal temática e o morfema de particípio passado (ALI, 1971: 237). Com essas palavras, não é correto dizer que há elementos epentéticos

$\begin{array}{lll}\text { (31) lav-a-r } & \text { lav-a-do } & \text { lav-a-d-eira } \\ \text { vend-e-r } & \text { vend-i-do } & \text { vend-e-d-or }\end{array}$

Em algumas palavras derivadas (32), constata-se que ocorre algum tipo de alteração na consoante ou na vogal da última sílaba do radical. Algumas receberam uma consoante epentética, outras, não. Tais palavras apresentam problemas de certa forma idiossincráticos, que se explicam apenas através de considerações de natureza histórica, por exemplo, da maneira como essas palavras foram incorporadas à língua, vindas do Latim.

\begin{tabular}{|c|c|c|}
\hline (32) & ler & lei-t-ura \\
\hline & mão & manu-al ${ }^{21}$ \\
\hline & lado & late-r-al \\
\hline & homem & hom-únc-ulo \\
\hline
\end{tabular}

A palavra homem apresenta algumas peculiaridades no radical, em formas derivadas como bominho, bomúnculo, ao lado da forma como homenzarrão, homenzinho. A palavras construtor tem também a forma construidor. Da palavra chapéu deriva-se uma palavra como chapeleira, como de tonel vem toneleiro, o que mostra que o último elemento do input da palavra chapéu apresenta um problema particular: é com /w/ ou com /L/? - (cf., ainda chapéus e não * chapéis - tonéis e não *tonéus). Há, ainda, uma série de palavras que apresentam problemas diversos, fugindo do padrão comum da língua, como, por exemplo, pederneira (de pedra), islâmico (de Islã), ministério (cf. ministro), maturidade (de maduro), etc. 
No tableau (34), apresenta-se a avaliação de bomúnculo. Para que essa forma seja admissível na língua, o arquifonema /N/ precisa cair, o que pode ser feito obrigando a aplicação da restrição de SANDHI. Se houver violação, será fatal, pois o resultado produzirá candidatos inaceitáveis.

(33) Ranking: SANDHI $>$ DeP-IO $>$ MAX-IO ; Align[F].

\begin{tabular}{|c|c|c|c|c|}
\hline$(34) /$ o.meN $+\mathrm{uN} . \mathrm{kul}+\mathrm{u} /{ }^{22}$ & SANDHI & DEP-IO & MAX-IO & ALIGH[F] \\
\hline a. ho.mún.cu.lo & & & $* *$ & $* *$ \\
\hline b. ho.me.nún.cu.lo & $* !$ & & & $* *$ \\
\hline c. ho.men.zún.cu.lo & $* !$ & $* !$ & & $*$ \\
\hline
\end{tabular}

Para que a regra de sândi se aplique no input/o.meN + uN.kul $+\mathrm{u}$ /, foi preciso violar duas vezes a restrição MAX-IO. O alinhamento dos segmentos, neste caso, é irrelevante. Porém, poder-se-ia reformular a restrição de alinhamento, especificando as bordas (direita / esquerda) em uma restrição do tipo AlignR(edge $L$ ), Alıgn $L(\operatorname{edge} L)$, etc. Neste caso, a violação do alinhamento à esquerda seria suportável ( bomúnculo levou o sufixo /-uN.kul+u/ uma sílaba à esquerda), porém, à direita, seria fatal ( *homenúnculo levou a nasal da coda da sílaba final do radical para onset da primeira sílaba do sufixo, havendo, neste caso, uma falta de alinhamento à direita). $\mathrm{O}$ mesmo problema do tableau (34) pode ser resolvido através da restrição *Liaison, uma vez que houve uma aplicação indevida da regra de liaison em (34b). Entretanto, a solução apresentada em (34) parece ser a mais simples. ${ }^{23}$

Palavras como goleiro e maldade são derivadas de gole de mal - radicais que terminam em /L/. Na primeira palavra, aplica-se a regra de liaison e o arquifonema fica plenamente especificado como uma lateral alveolar no onset da primeira sílaba do sufixo. Na segunda palavra, o arquifonema realiza-se como parte de um ditongo, formado com a vogal precedente. Como o radical termina com um elemento na coda, aplica-se a regra geral de epêntese, com a inserção 
da consoante [d]. A avaliação dessas duas palavras é apresentada em (36) e (37).

(35) Ranking: *Hiatus $>$ Dep-IO $>$ Liaison $>$ Align $[\mathrm{F}]$.

\begin{tabular}{|l|c|c|c|c|}
\hline (36) goL + ei.r + o & *HiATUS & DEP-IO & LiAisON & AligN[F] \\
\hline a. go.lei.ro & & & & $* *$ \\
\hline b. gow.ei.ro & $* !$ & & $*$ & $*$ \\
\hline c. gow.zei.ro & & $* !$ & $*$ & $*$ \\
\hline
\end{tabular}

\begin{tabular}{|l|c|c|c|c|}
\hline (37) $\mathrm{maL}+$ a.de & ALIGN $[\mathrm{F}]$ & FaITH[CoR] & Liaison & DeP-IO \\
\hline$\varpi$ a. maw.da.de & & & $*$ & $*$ \\
\hline b. ma.la.de & $* !$ & & & \\
\hline c. maw.ka.de & & $* !$ & $*$ & $* !$ \\
\hline d. maw.za.de & & & $*$ & $* !$ \\
\hline
\end{tabular}

A palavra goleiro apresenta uma violação de alinhamento, transferindo a lateral da coda para a posição de onset. Com isso, não foi aplicada a regra de epêntese, que gerou um candidato inaceitável em (36c). O candidato * goweiro ficou com um hiato na juntura, formado por dois ditongos decrescentes, o que não é permitido na língua. Somente seria aceitável um hiato com dois ditongos, se houvesse um glaide ambissilábico, como em exemplos do tipo meiia, Mau-uá, etc.

A restrição de alinhamento proíbe a aplicação da regra de liaison, como aconteceu com o candidato (37b), obrigando a aplicação da epêntese, como aconteceu com (37a). Em (37), a consoante epentética prevista é [d] e não [k] ou [z]. Portanto, quando ocorrer a epêntese de [d], haverá uma violação suportável de DepIO, mas com outras consoantes, a violação será fatal, como em (37c) e $(37 d)$.

Usando as restrições de alinhamento propostas acima, veja as avaliações de alguns casos, no tableau (40). 
(38) Aligh $L(\operatorname{Edge} L)$, etc. manda alinhar as bordas da direita $(R)$ ou da esquerda (L) da juntura morfemática interna de palavras, ou seja, proíbe a aplicação de regras como sândi e liaison.

(39) Ranking: $\operatorname{Aligh} L(\operatorname{Edge} L) ; \operatorname{Aligh} L(\operatorname{Edge} R) ; \operatorname{Aligh} R(\operatorname{Edge} R) ; \operatorname{Aligh} R(\operatorname{Edge} L)$.

\begin{tabular}{|c|c|c|c|c|}
\hline $\begin{array}{ll}\text { (40) } & \text { maL + a.de } \\
\text { goL + ei.r + o } \\
\text { o.meN + uN.ku.l + o }\end{array}$ & $\begin{array}{c}\text { Aligh } L \\
(\operatorname{EdgE} L)\end{array}$ & $\begin{array}{c}\text { Align } L \\
(\operatorname{EdgE} R)\end{array}$ & $\begin{array}{c}\text { Aligh } R \\
(\operatorname{Edge} R)\end{array}$ & $\begin{array}{l}\text { Aligh } R \\
(\operatorname{EDGE} L)\end{array}$ \\
\hline a. maw.da.de & & $*$ & & $*$ \\
\hline b. ma.la.de & $* !$ & & $* !$ & \\
\hline c. go.lei.ro & * & & $*$ & \\
\hline d. gow.ei.ro & & $* !$ & & $* !$ \\
\hline e. ho.mún.cu.lo & & & $*$ & \\
\hline f. ho.me.nún.cu.lo & $* !$ & & $* !$ & \\
\hline
\end{tabular}

\section{OS SUFIXOS DE GRAU}

Os sufixos de grau têm sido considerados como pertencentes a duas categorias diferentes, uma que começa com a consoante - $z$ (-zinho, -zão) e outra sem essa consoante (-inho, - $\tilde{a} o$ ). Como tem mostrado LEE (1995: 75-84), a primeira categoria funciona como uma palavra fonológica independente ${ }^{24}$, produzindo a formação de palavras do tipo composição e não derivação, coisa que não acontece com os sufixos da segunda categoria (ANDRADE, 1994: 113-115). Dois fatos importantes mostram tal divisão. Com -zinho, as vogais médias baixas do radical não sofrem a regra de alçamento e podem produzir colisão de acentos (41). As razões prosódicas ${ }^{25}$ e da qualidade das vogais levam à divisão estabelecida acima. De acordo com esta proposta, o - $z$ - pode, ainda, ser considerado uma consoante epentética, sendo inserido em contextos específicos, como os apontados neste trabalho. Dentro desse quadro, a aplicação da epêntese é fator condicionante das demais características atribuídas aos sufixos de grau. 


\section{(41) cajúzínho sofázínho \\ arróz-dóce consultór-chéfe}

O fato de as formas diminutivas apresentarem a inserção de uma consoante $-z$ - mostra que o radical mais o diminutivo seguem a regra geral de derivação, uma vez que na composição não há consoantes epentéticas. ${ }^{26} \mathrm{Na}$ verdade, um estudo mais amplo da formação de palavras em Português pode mostrar que esses 'sufixos' se alinham com os prefixos, formando um processo 'derivacional' próprio - como foi dito anteriormente. ${ }^{27}$ No output de alguns dialetos (42), ocorre uma forma variante [- i.u] do sufixo [- i.nu]. Tal vogal se mantém isolada na sílaba, se estiver precedida por outra vogal. Se o radical terminar por consoante, aplica-se a regra de liaison. Após a vogal nasal, ocorrerá a vogal de flexão de gênero, e um hiato nesse contexto.

\begin{tabular}{|c|c|c|c|}
\hline (42) & casinha & casĩ.nha & ca.sĩ.a \\
\hline & jacarezinho & jacare.1̃.nho & jacare.1.u \\
\hline & heroizinho & heroi.ĩ.nho & heroi.ĩ.u ${ }^{28}$ \\
\hline & paizinho & pai.̃.1.nho & pai.ĩ.u \\
\hline
\end{tabular}

Nos tableaux (43) e (44), apresenta-se a avaliação de dois exemplos de (42). A perda da consoante nasal é considerada uma violação de MAX-IO e de alinhamento, mesmo que o traço nasal tenha sido transferido para a vogal anterior. O fato de essa vogal ficar nasalizada representa uma violação de DEP-IO, diferente da epêntese. As formas variantes de (42) representam uma não-aplicação da regra de epêntese, quando devida, e a aplicação das regras de sândi, de liaison e de queda da nasal palatal, transferindo a nasalidade para a vogal anterior alta. Em termos fonotáticos, a presença do hiato é suportável, justamente porque a regra de epêntese não se aplica nesses casos.

\begin{tabular}{|l|c|c|}
\hline (43) ca.s $+\mathrm{a}+\mathrm{i} . \mathrm{nh}+\mathrm{a}$ & Max-IO & Align[F] \\
\hline \multirow{\sigma}{*}{ a. ca.si.nha } & $*$ & $* *$ \\
\hline b. ca.sĩ.a & $* *$ & $*$ \\
\hline
\end{tabular}




\begin{tabular}{|c|c|c|c|}
\hline (44) $\mathrm{pai}+\mathrm{i} \cdot \mathrm{nh}+\mathrm{o}$ & MAX-IO & Align $[\mathrm{F}]$ & DEP-IO \\
\hline a. pai.zi.nho & & * & * \\
\hline b. pai.î.u & * & & \\
\hline
\end{tabular}

\section{DERIVAÇÃO SUFIXAL COM PALAVRAS TERMINADAS EM /S/}

As palavras com derivação sufixal, terminadas em $/ \mathrm{S} /,{ }^{29}$ podem ter a última sílaba tônica ou átona. No primeiro caso, o arquifonema /S/ realiza-se como uma fricativa surda (45a). Quando a última sílaba é átona, o /S/ realiza-se como uma fricativa sonora (45b).

$\begin{array}{llll}\text { a. feliz } & \text { /feliS/ } & \text { felic-idade } & \\ \text { feroz } & \text { fferoS/ } & \text { feroc-idade } & \\ \text { sagaz } & \text { /sagaS/ } & \text { sagac-idade } & \\ \text { b. lápis } & \text { /lapiS/ } & \text { lapiz-inho } & \text { lapis-eira } \\ \text { pires } & \text { /piriS/ } & \text { pirez-inho } & \text { pirez-ão }\end{array}$

Os dados apresentados em (45) mostram que não há a necessidade de postular a presença de uma consoante epentética em nenhum caso. Os dados de (45a) fazem a liaison, mas não sonorizam a fricativa. Os dados de (45b) revelam a aplicação da regra de liaison, com a sonorização do arquifonema entre vogais. Compare essa situação com a sonorização da fricativa em juntura externa, que é uma regra geral da língua (46).

\begin{tabular}{|c|c|c|}
\hline 46) & migos & mew-za.mi.gus \\
\hline & feliz ano novo & fe.li-za.nu.no.vu \\
\hline & lápis azul & la.pi-za.zwu \\
\hline
\end{tabular}

A derivação que tem o radical terminado em /S/ torna esse segmento opaco para o estudo da epêntese, uma vez que a consoante epentética mais comum é - $z$-. Os dados de (45a) trazem evidência no sentido de não haver a necessidade de epêntese consonantal. O fato mais comum consiste em haver epêntese consonantal quando o radical terminar em arquifonema - (47). Tal 
constatação seria um argumento a favor da postulação de uma consoante epentética também no caso de /S/.

$\begin{array}{llll}\text { (47) jovem } & \text { /3oven/ } & \text { juven-t-ude } & \text { *juvenude } \\ \text { Belém } & \text { /beleN/ } & \text { Belen-z-inho } & \text { *Beleninho } \\ \text { sinal } & \text { /sinaL/ } & \text { sinal-z-inho } & \text { *sinalinho } \\ \text { túnel } & \text { /tuneL/ } & \text { tunel-z-inho } & \text { *tunelinho } \\ \text { ator } & \text { /atoR/ } & \text { ator-z-inho } & * \text { atorinho }\end{array}$

Os exemplos de (45a) e (45b) são avaliados nos tableaux (50) e (51) respectivamente. Para dar conta dos fatos levantados por esses dados, é preciso uma restrição que obrigue o vozeamento, quando se aplicar a regra de liaison. Isso pode ser resolvido com a restrição geral Vorce, que é irrelevante para outros contextos da palavra, mas sensível quando se trata da coda da sílaba final do radical, que se transformará em onset da primeira sílaba do sufixo.

(48) Voice: as consoantes devem ser vozeadas.

(49) Ranking: IDENT-IO[F] $>$ Voice $>$ DeP-IO $>$ Liaison.

\begin{tabular}{|c|c|c|c|c|}
\hline (50) fe.liS + i.da.de & IDENT-IO[F] & VOICE & DEP-IO & LIAISON \\
\hline a. fe.li.ci.da.de & & $* *$ & & \\
\hline b. fe.li.zi.da.de & $* !$ & $*$ & & \\
\hline
\end{tabular}

\begin{tabular}{|c|c|c|c|c|}
\hline (51) la.piS + ei.r + a & IDENT-IO[F] & VOICE & DEP-IO & LIAISON \\
\hline a. la.pi.zei.ra & $*$ & & & \\
\hline b. la.pi.cei.ra & & $* * !$ & & \\
\hline
\end{tabular}

Em felicidade, foi aplicada parte da regra de liaison, não houve epêntese e os traços dos segmentos do input apareceram no output - considerando-se que o /S/ seja 'não-vozeado'. A restrição Voice foi violada duas vezes, uma no caso do [f], que é irrelevante aqui, e outra no caso do [s].

Na palavra lapiseira, houve apenas uma violação suportável da restrição IDENT-IO[F], que espera que os traços dos segmentos do 
input estejam no output, uma vez que o /S/ apareceu na forma vozeada. Por outro lado, o não-vozeamento causa uma violação fatal na palavra *lapiceira.

\section{CONSOANTES "EVAPORADAS"}

Algumas palavras (52), que terminam por arquifonema, perdem-no quando é acrescentado um sufixo de grau. Sem a consoante da coda, aplica-se a regra de sândi, que faz com que a vogal átona final do radical caia, obrigando, em seguida, a aplicação da regra de liaison, que ressilabifica o contexto, passando a consoante final do radical para a posição de onset inicial do morfema seguinte.

\begin{tabular}{|c|c|c|c|}
\hline$(52)$ & Carlos & Car.1-i.nhos ${ }^{31}$ & Car.l-ão \\
\hline & Válter & Val.t-i.nho & Val.t-ão \\
\hline & Mílton & Mil.t-i.nho & Mil.t-ão \\
\hline & órgão & or.gu-i.nho & or.g-ão \\
\hline & túnel & tu.n-i.nho & tu.n-ãó ${ }^{32}$ \\
\hline & homem & hominho & homão \\
\hline
\end{tabular}

A seguir, mostra-se como as restrições dão conta de escolher como formas ótimas o que foi apresentado em (52) e, por outro lado, como deixam de lado as formas consideradas inaceitáveis na língua, ainda de acordo com os dados de (52).

(53) NoCoda: as sílabas acabam por vogal.

(54) Ranking: NoCoda $>$ Align[F] $>$ SANDHI $>$ Dep-IO.

\begin{tabular}{|c|c|c|c|c|c|}
\hline $\begin{array}{c}\text { (55) CaR.loS }+ \text { i.nh+o } \\
\text { CaR.loS }+\tilde{a}+\mathrm{O}\end{array}$ & NoCoda & Align[F] & MAX-IO & SANDHI & DeP-IO \\
\hline Car.li.nhos & $* *$ & $* * *$ & $*$ & & \\
\hline Car.lão 33 & $* *$ & $* *$ & $* *$ & & \\
\hline Car.lãos & $* * !$ & $* * * !$ & $*$ & & \\
\hline Car.lo.zi.nho & $*$ & $* *$ & & & \\
\hline
\end{tabular}




\begin{tabular}{|c|c|c|c|c|c|}
\hline $\begin{array}{c}\text { (56) Val.teR }+ \text { i.nh+o } \\
\text { Val.teR }+\tilde{\mathrm{a}}+\mathrm{O}\end{array}$ & NoCoda & Align[F] & MAX-IO & SANDHI & DeP-IO \\
\hline Val.ti.nhor & $* * !$ & $* * * !$ & $*$ & & \\
\hline$*$ Val.ti.nho & $*$ & $* *$ & $* *$ & & \\
\hline Val.tão & $* *$ & $* *$ & $* *$ & & \\
\hline Val.te.rão & $* *$ & $* *$ & & & \\
\hline Val.ter.zão & $* * *$ & $*$ & & & \\
\hline
\end{tabular}

Nos tableaux (55) e (56), as restrições NoCoda e Align[F] apresentam o mesmo valor para avaliar os candidatos de (52). As palavras *Carlãos e * Valtinhor colocaram a consoante da coda final do radical na coda da sílaba final do sufixo, o que não é admissível em português. Portanto, houve uma violação fatal de alinhamento também.

No caso desses nomes com sufixo de grau, a simples aplicação da regra de liaison é proibida (cf. *Carlozinho, *Valterão). Em lugar dessa regra, deve-se aplicar a regra de sândi e, para isto, a consoante final do radical precisa cair - violação de MAX-IO.

Embora haja um contexto favorável para a aplicação da epêntese em uma palavra como Valter + inho / ão, as formas Valterzinho e Valterzão são toleradas por alguns falantes ou em algum estilo de fala, ${ }^{34}$ mas não representam a forma ótima Valtinho e Valtão. Por isso, foi colocada uma violação com relação à restrição DeP-IO. A não-indicação de Valterzão como forma ótima pode ser constatada pela ausência do ícone da mão com o dedo indicando, que não foi colocado na frente do candidato.

\section{CONCLUSÃO}

O presente trabalho mostrou que a ocorrência das consoantes epentéticas em juntura morfemática interna de palavras ocorre para evitar a presença de hiatos ou para preencher o onset da sílaba inicial do segundo morfema, com o objetivo de não desfazer a estrutura 
silábica das palavras, como acontece no caso da aplicação das regras de sândi ou de liaison, quando a consoante da coda final de uma palavra torna-se onset da palavra seguinte. Mostrou, ainda, que os processos de epêntese, de sândi e de liaison se relacionam. Os segmentos consonantais, que podem ser consoantes epentéticas, apresentam o lugar de articulação coronal.

Finalmente, este trabalho mostrou que o processo de derivação revela alguns problemas específicos, quer com relação à constituição fonológica do radical, quer com relação à presença ou não de uma consoante no início do sufixo.

Com relação à interpretação do fenômeno dentro do quadro da TO, optou-se por usar de modo preferencial as restrições mais gerais, sempre que possível e na sua formulação mais abrangente. Como a TO é de cunho gerativo, a busca pela universalidade é um ideal que se deve sempre procurar alcançar.

\section{NOTAS}

* O presente trabalho foi financiado em parte com verba do CNPq (L.C. Cagliari - Proc. 301450 / 78-1 (RN) e da FAPESP (G.Massini-Cagliari - Projeto Fonologia do Português Arcaico, No. 97/12447-5).

${ }^{1}$ Com relação a esse fenômeno, veja, por exemplo, PIGGOTT \& SINGH (1985).

${ }^{2}$ MASSINI-CAGLIARI (1999) apresenta um estudo sobre os processos de paragoge e epêntese, mostrando que a paragoge, diferentemente de outros processos de inserção, está ligada a fatores rítmicos.

${ }^{3}$ Os segmentos africados e as nasais homorgânicas apresentam características fonéticas e fonológicas próprias e não são interpretados como elementos epentéticos, nem como casos de segmentos intrusivos.

${ }^{4}$ Clements faz o seguinte comentário: "Unlike other types of epenthesis, there seems to be no generale rationale for intrusive stop formation in terms of preferred syllable types" (1987: 4).

${ }^{5} \mathrm{O}$ fato de o segmento intrusivo ser uma oclusiva oral mostra, por outro lado, que sua ocorrência depende de restrições que, na análise tradicional, têm sido atribuídas a uma escala de sonoridade (tipo SELKIRK, 1984: 112; HOGG \& McCULLY, 1987:33). Em outras palavras, isto significa que esse fenômeno está 
ligado por uma teoria da marca (markedness theory) e não ocorre apenas como fato idiossincrático próprio de cada língua.

${ }^{6}$ Para uma introdução à Teoria da Otimalidade, veja, entre outros, ARCHANGELI \& LANGEDOEN (1997), ROCA (1997), KAGER (1999). No site da Internet bttp:// ruccs.rutgers.edu/roa.btml, há uma lista de artigos do arquivo ROA (Rutgers Optimality Archive), com trabalhos baseados na TO, que podem ser copiados.

${ }^{7} \mathrm{~S}_{2}$ refere-se à cadeia de elementos do output e $\mathrm{S}_{1}$ refere-se à cadeia de elementos do input (McCARTHY \& PRINCE, 1997: 60). Em outras palavras, a restrição DePIo diz que é proibida a inserção de segmentos no output.

${ }^{8}$ Levando em conta fenômenos como acento, sândi, epêntese, qualidade vocálica, estrutura de sílaba, nota-se que os prefixos funcionam como uma categoria morfológica diferente das raízes e dos sufixos, assemelhando-se mais às formações com os diminutivos do tipo -zinho, e dos advérbios em -mente. Os prefixos não admitem a epêntese nem o sândi: soerguer, antiindependência; mantêm o acento e a qualidade vocálica de vogais médias baixas, como em pós-graduação, précarnaval (no entranto, cf. prêtônica e pôstônica); e podem ocorrer sem repetição em mais de um radical, como em pré e pós-modernismo. Além disso, os prefixos sofrem processos de assimilação, como em ilegal (de $i n+l e g a l$ ). Se as formações como -zinho e -mente não tiverem, de fato, uma consoante epentética, a semelhança entre esses elementos é muito grande. Por causa dessas características, seria mais adequado dizer que essas formas morfológicas não representam nem um processo de derivação, nem de composição, mas um outro tipo. Tal assunto merece uma discussão à parte e uma pesquisa especial.

${ }^{9}$ Neste trabalho, a fronteira morfemática é marcada com o travessão ou com o sinal de mais.

${ }^{10} v t$ refere-se a vogal tônica e va refere-se a vogal átona.

${ }^{11}$ A indicação de fronteira silábica é marcada com um ponto.

12 Além disso, pode formar ditongo com a vogal anterior, como em caféico, prosaico, etc.

13 Veja BISOL (1996).

${ }^{14}$ Essa restrição poderia ser formulada também como IDENT(I/O)[CoR]. A respeito da Fidelidade na TO, veja BECKMAN (1998).

${ }^{15}$ Algumas alterações que ocorrem no output com relação ao input necessitam de restrições específicas ou de modificações no ranking. Essas restrições especiais acabam criando estruturas que ocorrem em poucas línguas ou até mesmo em uma única língua. Todavia, sempre que possível, é preferível usar uma restrição de caráter universal na sua forma negativa do que criar uma restrição muito excepcional. 
${ }^{16}$ Essa restrição poderia ser estabelecida apenas como NoCor.

${ }^{17}$ Para um estudo do Princípio de Contorno Obrigatório (OCP) na Teoria da Otimalidade, veja MYERS (1994).

${ }^{18} \mathrm{Na}$ verdade, o fenômeno se estende aos sufixos de grau, que começam por $-z$ -

${ }^{19}$ Para uma discussão detalhada desses fenômenos, veja, entre outros autores LEE (1995) e CAGLIARI (1997).

${ }^{20}$ Com relação à necessidade de uso de uma restrição tão particular, é bom lembrar o que diz ARCHANGELI (1997: 15): "The ideal which Optimality research aims for (and sometimes appears to fall short of) is to provide evidence of the universality of each constraint necessary for some particular language. For constraints such as the one posited for syllabification in this chapter, universality is readily motivated; there are numerous analyses involving constraints whose status as a universal is minimal at best. At this point, it is unclear whether this is a weakness of the model itself, or a weakness of the analyses."

${ }^{21}$ Os exemplos de (32) mostram que existe uma tendência para o arquifonema nasal /N/ de final de palavra realizar-se como [n], quando recebe um sufixo, se não houver a inserção de uma consoante epentética. Veja os exemplos: fim-final; grão - grânulo; órgão - organista; jovem - juventude, Juvenal; comum comunidade, comumente, etc. Por outro lado, islamita e islâmico vêm de Islã. Para algumas questões relativas à nasalidade e a TO, veja o artigo de BATTISTI (1998).

${ }^{22}$ Em alguns dialetos, em lugar da vogal média baixa posterior, ocorre uma vogal média alta no radical.

${ }^{23}$ Como a palavra homem [omẽi] apresenta a variante [omI], o input poderia ser formado de /omi+uN.kul+u/. Assim, o contexto já estaria pronto para a regra de sândi ou apenas de liaison e não de epêntese. Problemas como este mostram que a constituição do input ainda não é uma questão bem definida na TO.

${ }^{24}$ Fato semelhante é atribuído também à terminação - mente, que forma advérbios - cf. somente, certamente, etc. (CÂMARA Jr. 1985: 121; LEE, 1995: 75-84; CAGLIARI, 1999).

${ }^{25}$ É preciso levar em conta também o fato de a língua portuguesa manter desde o latim antigo uma tendência a evitar a colisão de acentos, fazendo com que a primeira sílaba das palavras receba um acento que, em geral, representa o deslocamento de um acento secundário. Assim, palavras como cafezinho e cajuzinho são pronunciadas comumente como càfezínho e càjuzínho e, somente em uma situação de velocidade lenta, com a colisão de acentos cafêzínho e cajùzínho. A qualidade da vogal [ع] e [u], típicas de sílaba tônica, não deve ser confundida com um padrão rítmico em que elas são necessariamente acentuadas. (Com relação a algumas questões de prosódia e epêntese, veja HOBERMAN, 1995; STEELE \& AUBER, 1999). 
${ }^{26}$ Celso Cunha, em sua Gramática do português contemporâneo, diz o seguinte: "Excetuando-se o caso das palavras terminadas em $-s$ e $-z$, que naturalmente exigem a forma -inho (pires-inho, rapaz-inho), não é fácil indicar as razões que comandam a escolha entre -inho e-zinho. Sente-se que muitas vezes a seleção está ligada ao ritmo da frase. Por outro lado, verifica-se uma preferência na linguagem culta pelas formações com -zinho, no evidente intuito de manter íntegra a pronúncia da palavra derivante; a linguagem popular, no entanto, simplificadora por excelência, tende para as formações com -inho." (CUNHA, 1978: 66).

${ }^{27}$ Veja o comentário da nota 8.

${ }^{28}$ Nestes casos, o ditongo pode se reduzir a um monotongo também, ficando he.ró.ĩ.u.

${ }^{29}$ A noção de arquifonema não cabe bem na TO. No presente caso, poder-se-ia ter apenas $/ \mathrm{s} / \mathrm{em}$ lugar de $/ \mathrm{S} /$. O fato de o arquifonema ser um segmento subespecificado causa problemas especiais nas avaliações da TO.

${ }^{30}$ Entretanto, veja uma palavra como sinaleira.

${ }^{31}$ É muito curiosa a presença do 's' final em Carlinhos, dando a impressão de que o sufixo foi intercalado.

${ }^{32}$ Esse tipo de formação lexical apresenta um estilo informal de uso da linguagem. Esse processo não se aplica, se a palavra for oxítona, como em Luiz, Luizinho, *Luinho(s); canhão, canhãozinho, *canbinho.

${ }^{33}$ No caso dos ditongos decrescentes, o segundo elemento pertence à coda, portanto, o ditongo não está sendo interpretado como ramificação do núcleo.

${ }^{34}$ Porém, são consideradas formas marcadas. 


\section{REFERÊNCIAS BIBLIOGRÁFICAS}

ALI, L.H., DANILOFF, R.G., HAMMARBERG, R. Intrusive stops in nasal-fricative clusters: an aerodynamic and acoustic investigation. Phonetica, 36, p. 85-97, 1979.

ALI, M. Said. Gramática histórica da língua portuguesa. 7. ed. Rio de Janeiro: Livraria Acadêmica, 1971.

ANDERSON, James M. Historical Linguistics. In: MALMKJAER, Kirsten (Ed.). The linguistics encyclopedia. New York: Routledge, 1991.

ANDRADE, Ernesto d'. O acento de palavras em português. Temas de Fonologia. Lisboa: Edições Colibri, p. 107-130, 1994.

ARCHANGELI, Diana, LANGENDOEN, D. Terence. Optimality Theory - an overview. Oxford: Blackwell Publishers Inc., 1997.

BATTISTI, Elisa. A nasalização no português brasileiro pela teoria da otimidade. Revista de Estudos da Linguagem. Belo Horizonte: Faculdade de Letras da UFMG, v.7, n.1, p.59-89, 1998.

BECKMAN, Jill. Positional faithfulness. University of Massachusetts, Ph. D. dissertation. 1998.

BERNHARDT, Barbara Handford, STEMBERGER, Joseph Paul. Handbook of phonological development, from the perspective of constraint-based nonlinear phonology. San Diego: Academic Press. (cf. Appendix C : List of the constraints of Optimality Theory, p. 705-737), 1998.

BISOL, L. O sândi e a ressibilação. Letras de Hoje. Porto Alegre, v. 31-2, n. 104, 1996.

CAGLIARI, Luiz Carlos. Fonologia do português: análise pela geometria de traços. Campinas: Edição do Autor, 1997.

Aspectos morfofonológicos dos advérbios em -mente. Comunicação apresentada no XXII Symposium on Portuguese Traditions, 1999, UCLA, 1999.

CÂMARA Jr., J. Mattoso. História e estrutura da língua portuguesa. Rio de Janeiro: Padrão, 1985.

CASALI, Roderic F. Resolving Hiatus. Los Angeles: University of California, Ph.D. dissertation, 1996.

CLEMENTS, G. N. Phonological feature representation and the description of intrusive stops. In: Parasession on autosegmental and metrical phonology. Chicago Linguistic Society, p.1-22, 1987.

. The role of the sonority cycle in core syllabification. In: Working Papers of the Cornell Phonetics Laboratory, n. 2, April, p. 1-68, 1988. 
CONTRERAS, Heles. Spanish epenthesis and stress. University of Washington Working Papers in Linguistics 3: 9-33, 1977.

CUNHA, Celso. Gramática do português contemporâneo. 7. ed. rev. Belo Horizonte: Bernardo Álvares, 1978.

FOURAKIS, M., PORT, R. Stop epenthesis in English. In: Research in Phonetics and Computational Linguistics. Report № 5, Departments of Linguistics and Computer Science, Indiana University, Bloomington, p. 37-71, 1986.

HARRIS, James. Epenthesis processes in Spanish. In: NEIDLE, Carole and CEDEÑO, Rafael A. Nuñez (Ed.s) Studies in Romance Languages, p.107-122, 1987.

HOBERMAN, Robert. Current issues in semitic phonology. In: GOLDSMITH, John A. (Ed.). The Handbook of phonological theory. Oxford: Blackwell Publishers, p. 839-847, 1995.

HOGG, Richard, McCULLY, C. B. Metrical phonology: a coursebook. Cambridge: Cambridge University Press. 1987.

HUBER, Joseph. Gramática do português antigo. Lisboa: Fundação Calouste Kulbenkian, 1986.

KAGER, René. Optimality Theory. Cambridge: Cambridge University Press, 1999.

LEE, Seung-Hwa. Morfologia e fonologia lexical do português do Brasil. Campinas: UNICAMP - IEL - DL, 1995. (Tese de Doutorado)

Sobre a formação de diminutivos no português brasileiro. Revista de Estudos da Linguagem. Belo Horizonte: Faculdade de Letras da UFMG, v. 8, n. 1, p.113-124, 1999.

LIPSKI, John M. Epenthesis vs. elision in Afro-Iberian Language: a constraintbased approach to creole phonology. Communication presented to LSRL, April 9, University of Michigan, Ann Arbor. 1999.

LYONS, John. Introdução à Lingüistica Teórica. São Paulo: Cia. Editora Nacional/ Edusp, 1979.

MASSINI-CAGLIARI, Gladis. Cantigas de amigo: do ritmo poético ao lingüístico. Um estudo do percurso histórico da acentuação em português. Campinas: UNICAMP - IEL - DL, 1995. (Tese de Doutorado)

Epêntese e paragoge: processos fonológicos distintos. Comunicação apresentada no II Congresso Nacional da ABRALIN. Florianópolis: Universidade Federal de Santa Catarina (UFSC). 25 a 27 de fevereiro de 1999.

McCARTHY, John J. Sympathy, Cumulativity, and the Duke-of-York Gambit. Amherst: University of Massachussets - (ROA 315-0499). 1999.

McCARTHY, John J., PRINCE, Alan. Generalized alignment. Yearbook of Morphology, 79-153 - (ROA 7-0000). 1993. 
McCARTHY, John J., PRINCE, Alan. Faithfulness and reduplicative identity. In: BECKMAN, Jill; DICKEY, Laura Walsh, URBANCZYK, Suzanne (Ed.s). Papers in Optimality Theory. University of Massachusetts Occasional Papers in Linguistics N. 18. Amherst: Graduate Linguistic Student Association, p. 249384 - (ROA, p. 148). 1995.

. Faithfulness and Identity in Prosodic Morphology - (ROA 216-0997). (este artigo será publicado em KARGER, Rene; van der HULST, Harry and ZONNEVELD, Wim (Ed.s). The prosody-morphology interface. Cambridge: Cambridge University Press. 1997.

MONTEIRO, José Lemos. Morfologia portuguesa. Campinas: Pontes. 1991.

MYERS, Scott. OCP effects in Optimality Theory - (ROA 6-0000). 1994.

PIGGOTT, G. L., SINGH, R. The phonology of epenthetic segments. CJLIRCLl, n.30, p.415-451, 1985.

PRINCE, Alan, SMOLENSKY. Optimality Theory: constraint interaction in Generative Grammar. Rutgers University. Ms. 1993.

ROCA, Iggy (Ed.). Derivations and constraints in phonology. Oxford: Clarendon Press, 1997.

SELKIRK, E. O. On the major class features and syllable theory. In: ARONOFF, M., OEHRLE, R.T. (Ed.'). Language sound structure: studies in phonology presented to Morris Halle by bis teacher and students. Cambridge: Mass.: MIT Press, 1984.

SHERRARD, Nicholas. Questions of priorities: an introductory overview of Optimality Theory in Phonology. In: ROCA, Iggy (Ed.). Derivations and Constraints in Phonology. Oxford: Clarendon Press, p.43-89, 1997.

STEELE, Jeffrey, AUGER, Julie. Accounting for intraspeaker variation within a constraint-based framework: a case study of vocalic epenthesis in Vimeu Picard. Communication presented to LSRL 29, April 8-11, 1999.

VOGEL, I. External sandhi rules operating between sentences. In: ANDERSEM, H. (Ed.). Sandhi Phenomena in the Languages of Europe, p. 55-64. Berlin: Mouton, 1986.

WETZELS, W.L. The historical phonology of intrusive stops - a nonlinear description. CJLIRCL, 30, p. 285-333, 1985. 